\title{
Using microcantilever sensors to measure poly(lactic-co-glycolic acid) plasticization by moisture uptake
}

\author{
Alves, Gustavo Marcati A.; Bose-Goswami, Sanjukta; Mansano, Ronaldo D.; Boisen, Anja
}

Published in:

Polymer Testing

Link to article, DOI:

10.1016/j.polymertesting.2017.12.017

Publication date:

2018

Document Version

Peer reviewed version

Link back to DTU Orbit

Citation (APA):

Alves, G. M. A., Bose-Goswami, S., Mansano, R. D., \& Boisen, A. (2018). Using microcantilever sensors to measure poly(lactic-co-glycolic acid) plasticization by moisture uptake. Polymer Testing, 65, 407-413. https://doi.org/10.1016/j.polymertesting.2017.12.017

\section{General rights}

Copyright and moral rights for the publications made accessible in the public portal are retained by the authors and/or other copyright owners and it is a condition of accessing publications that users recognise and abide by the legal requirements associated with these rights.

- Users may download and print one copy of any publication from the public portal for the purpose of private study or research.

- You may not further distribute the material or use it for any profit-making activity or commercial gain

- You may freely distribute the URL identifying the publication in the public portal 


\title{
Using microcantilever sensors to measure poly(lactic-co-glycolic acid) plasticization by moisture uptake
}

\author{
Gustavo Marcati A. Alves ${ }^{\mathrm{a}, *}$, Sanjukta Bose Goswami ${ }^{\mathrm{b}}$, Ronaldo D. Mansano ${ }^{\mathrm{a}}$, Anja Boisen ${ }^{\mathrm{b}}$ \\ a Integrated Systems Laboratory, Polytechnic School of São Paulo University, São Paulo, Brazil \\ b Department of Micro and Nano Technology, Technical University of Denmark, Kgs. Lyngby 2800, Denmark
}

\section{A R T I C L E I N F O}

\section{Keywords:}

Microcantilever

Thermal analysis

Plasticization

Poly(lactic-co-glycolic acid)

Glass transition

\begin{abstract}
A B S T R A C T
Polymeric materials absorb water when exposed to humidity or in contact with aqueous solutions. The polymer and water molecules interact, changing the physicochemical parameters of the material; the most noticeable effect is a decreased glass transition temperature $\left(T_{g}\right)$, known as plasticization. We used microcantilever sensors to measure the $T_{g}$ versus moisture content in poly(lactic-co-glycolic acid) (PLGA), a biodegradable polymer used in implants and as a drug carrier. We demonstrate a concomitant measurement of the mass absorption and $T_{g}$ using nanograms of material and an inexpensive setup. The standard deviation of $T_{g}$ for this system was $0.025^{\circ} \mathrm{C}$, and the variation in $T_{g}$ with respect to a $1 \% \mathrm{RH}$ change was clearly resolved. The decrease in the $T_{g}$ of PLGA was linear $\left(\mathrm{R}^{2}=0.99\right)$ at a rate of $6.03 \pm 0.57^{\circ} \mathrm{C}$ per mass $\%$ of water absorbed. The initial dry $T_{g}$ of PLGA was extrapolated to $41.24 \pm 0.07^{\circ} \mathrm{C}$.
\end{abstract}

\section{Introduction}

PLGA (poly(lactic-co-glycolic acid)) is a biodegradable polymer used in drug delivery systems and implantable medical devices for several drugs approved by the US Food and Drug Administration. When glassy amorphous polymers, such as PLGA, are immersed in aqueous solutions or absorb moisture from the air, they can undergo physicochemical changes; the most notable change is the reduced glass transition temperature $\left(T_{g}\right)$, which is known as plasticization [1].

Water has a $T_{g}$ of approximately $-135^{\circ} \mathrm{C}$, while that of PLGA is approximately $50^{\circ} \mathrm{C}$; hence, small additions of water in the polymer decrease its overall $T_{g}$ to temperatures below normal body temperature. At temperatures above $T_{g}$, the glassy polymer acquires rubbery characteristics, the viscosity of the material decreases, and the elastic modulus decreases by several orders of magnitude. In drug delivery systems, the viscosity is an important parameter because structural relaxation alters the polymer volume, in turn altering drug diffusivity and the drug release profile [2]. In addition, structural changes must be considered for structural devices, such as implantable scaffolds [3] in which the structural stiffness decreases above $T_{g}$.

Microcantilevers and microresonators have been successfully used to characterize the glass transition of materials in dynamic mode (e.g., using vibrations) and in static mode (using the deflection) [4-9]. These microstructures enable the use of smaller samples (by several orders of magnitude) than traditional bulk techniques, such as dynamic mechanical analysis or differential scanning calorimetry (DSC). Smaller samples exhibit faster equilibration times, enabling faster measurement of plasticization as the moisture equilibrium time is drastically reduced. The DSC measurement requires $5-10 \mathrm{mg}$ of sample; the PLGA equilibration time for this mass is approximately 4 days [10], while equilibration for the PLGA film in nanograms occurs within minutes [11]. The total measurement time of the $T_{g}$ under various humidity conditions can be decreased from several days to a few hours using nanograms of the sample.

In addition, the mass sensing capabilities of the microcantilevers are useful in plasticization studies based on water absorption because the mass of water uptake can be measured with respect to the relative humidity (RH). The mass resolution of the cantilevers can easily reach tens of picograms for micrometer-sized cantilevers [12]; this is sensitive enough to measure a water mass addition of approximately $0.01 \%$ in nanograms of the polymer.

We demonstrate an inexpensive microcantilever platform for polymer characterization to measure the evolution of $T_{g}$ and moisture absorption of the PLGA biopolymer deposited on cantilevers using a spray coating technique. Using this platform, the temperature and humidity can be controlled inside a flow cell; the resonant frequency and deflection of the cantilever chip is measured by a CD-ROM pickup. $T_{g}$ is measured using static deflection and the water uptake is measured based on the first-mode resonant frequency.

\footnotetext{
* Corresponding author

E-mail addresses: gmarcati@usp.br (G.M.A. Alves), sbos@nanotech.dtu.dk (S.B. Goswami), mansano@lsi.usp.br (R.D. Mansano), Anja.Boisen@nanotech.dtu.dk (A. Boisen).
} 


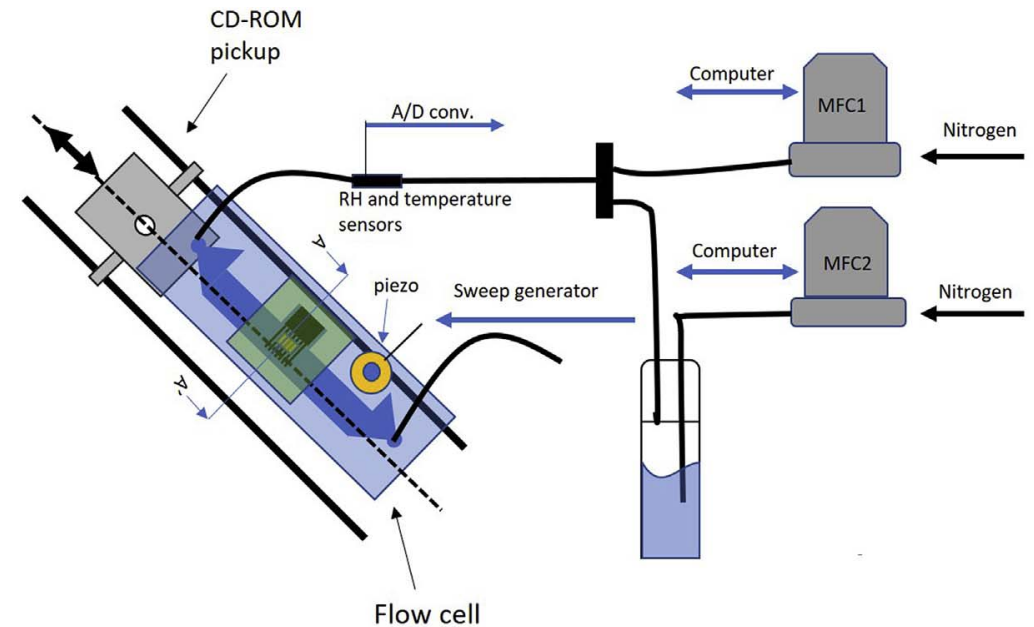

a)

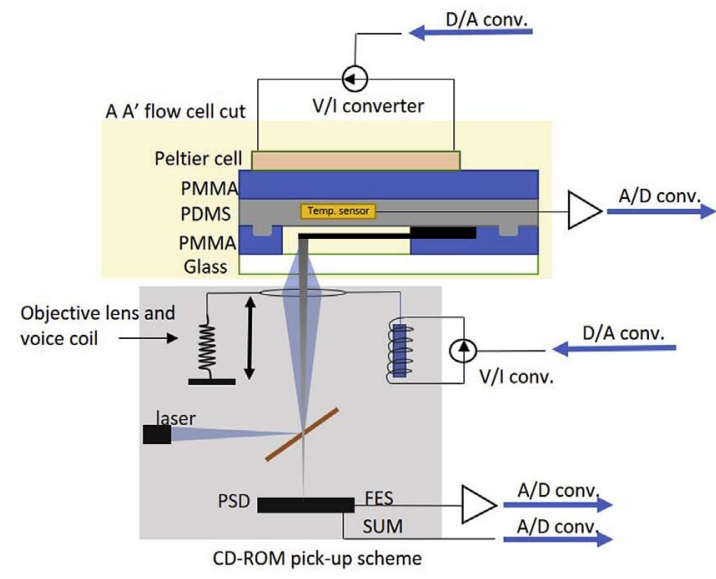

b)

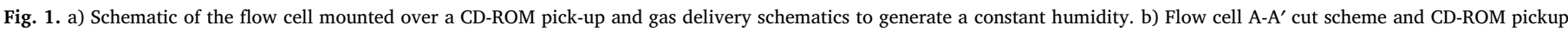
internal schematic.

\section{Materials and methods}

\subsection{Cantilever measurement system and gas supply}

A CD-ROM pick-up system was used to measure the cantilever displacement. This system can measure quasi-real time differential deflection of the cantilevers for small displacements or single cantilever deflection for large displacements. In addition, it can read the cantilever vibration in the kilohertz range in dynamic mode. A schematic of the system is depicted at Fig. 1(a).

The pick-up system uses the same mechanism as that for disc reading with a stepper motor that sweeps the laser head under the flow cell among the cantilevers. As described in detail elsewhere [13,14], the focus error signal (FES) was used in the linear region as a displacement signal between the cantilever and head. Because this linear region is very limited in span (around $8 \mu \mathrm{m}$ ), a closed loop scheme with a focus coil was used to achieve displacements in the millimeter range.

The focus coil was actuated using a digital proportional-integral controller to maintain the FES average around a proper setpoint, ensuring that the cantilever was always in focus. The displacement response of the lens showed a linear relationship with the focus coil current; therefore, the coil current could be used to measure the cantilever deflection after calibration of the displacement/current ratio.

The flow cell for the cantilevers was machined in a 1-mm-thick poly (methyl methacrylate) (PMMA) layer and glued to a glass microscope slide. A thick layer of polydimethylsiloxane (PDMS; around $500 \mu \mathrm{m}$ ) was molded using a complementary pattern to that machined in PMMA, providing an efficient seal for the cell when pressed with a top layer of PMMA. This reusable cell enabled the use of liquid or gas; a schematic of the cell is shown in Fig. 1(b). A Heraeus 4894-11 PT100 temperature sensor was integrated in the PDMS sealant layer for local cantilever sensing. The temperature was obtained using a four-probe scheme with a temperature-stable constant current generator. A Peltier cell was placed on top of the flow cell to actuate the temperature in the cantilever region. The power was delivered to the Peltier using a voltagecontrolled current source with a control voltage from a digital-to-analog converter. A digital proportional integral derivative (PID) temperature controller maintained the temperature within $\pm 0.01{ }^{\circ} \mathrm{C}$.

For the gas delivery system, two mass flow controllers (MKS Instruments) were controlled by a computer, and a Honeywell HIH4000 relative humidity sensor was placed in the intake gas line. This sensor had a nominal accuracy of $\pm 3 \% \mathrm{RH}$ and repeatability of $\pm 0.5 \%$. A constant flow of $50 \mathrm{sccm}$ controlled the ratio between the humidified and dry nitrogen in a digital closed loop PID device, achieving $\pm 0.1 \% \mathrm{RH}$ control. Due to its large dimensions, the humidity sensor could not be integrated into the flow cell; consequently, the measured humidity in the flow cell was subject to errors if the sensor and cell temperatures differed. To correct the humidity at the flow cell, a Heraeus 4894-11 PT100 temperature sensor was added in the intake gas line to measure the temperature of the gas near the humidity sensor. The temperature and humidity were used to calculate the partial pressure of the vapor in the intake lines using the Buck equation for water vapor pressure [15]. Assuming that the partial pressure of the vapor remained constant in the sensor and in the cell, the $\mathrm{RH}$ in the cell $\left(R H_{\text {cell }}\right)$ could be calculated using Eq. (1):

$R H_{\text {cell }}=R H_{\text {sensor }} \frac{\exp \left(\left(18.678-\frac{T_{\text {sensor }}}{234.5}\right)\left(\frac{T_{\text {sensor }}}{257.14+T_{\text {sensor }}}\right)\right)}{\exp \left(\left(18.678-\frac{T_{\text {cell }}}{234.5}\right)\left(\frac{T_{\text {cell }}}{257.14+T_{\text {cell }}}\right)\right)}$

where $R H_{\text {sensor }}$ is the humidity measured by the sensor, and $T_{\text {sensor }}$ and $T_{\text {cell }}$ are the temperatures $\left({ }^{\circ} \mathrm{C}\right)$ measured at the sensor and cell, respectively. A National Instruments NI-USB 6009 board with 14-bit resolution was used for signal acquisition and voltage actuation. This board was limited to a sampling rate of $15 \mathrm{kHz}$ for three-channel acquisition. The fast Fourier transform (FFT) analysis of the cantilever displacement was limited to an $8-\mathrm{kHz}$ bandwidth, which was sufficient to measure the first mode vibration of the cantilevers.

\subsection{PLGA film spray coating}

The PLGA thin film was spray coated over the cantilevers using an ExactaCoat spray coater (Sono-Tek). PLGA Resomer RG502 (Sigma Aldrich) was dissolved in dichloromethane (boiling point $=40^{\circ} \mathrm{C}$, density $=1.33 \mathrm{~g} / \mathrm{mL}$ at $20^{\circ} \mathrm{C}$ ) at $0.5 \%$ weight concentration and the spray coater atomizing nozzle was operated at $120 \mathrm{kHz}$ with $1.3 \mathrm{~W}$ of power; the polymer solution was injected at a flow of $100 \mu \mathrm{L} / \mathrm{min}$. Arrays of eight rectangular cantilevers were obtained from IBM ( $\mathrm{w}=100 \mu \mathrm{m}, \mathrm{L}=500 \mu \mathrm{m}$, and $\mathrm{t}=1 \mu \mathrm{m}$ ) and placed under the nozzle. The number of nozzle passes over the cantilever controlled the thickness of the thin film. After deposition, the film was annealed at $60{ }^{\circ} \mathrm{C}$ for $2 \mathrm{~h}$ for homogenization. The cross-section thickness of the resulting film 


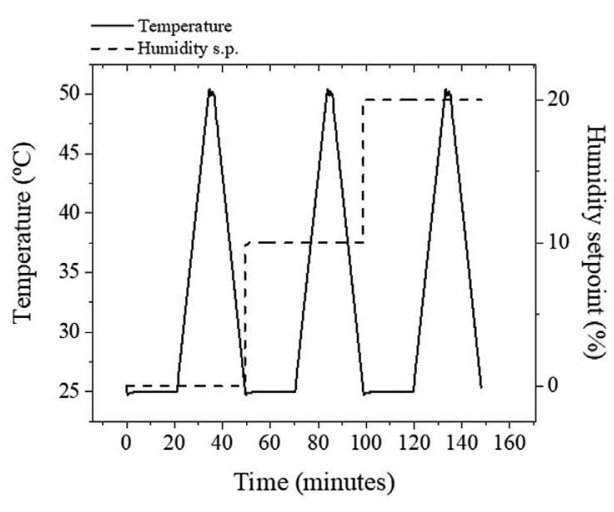

a)

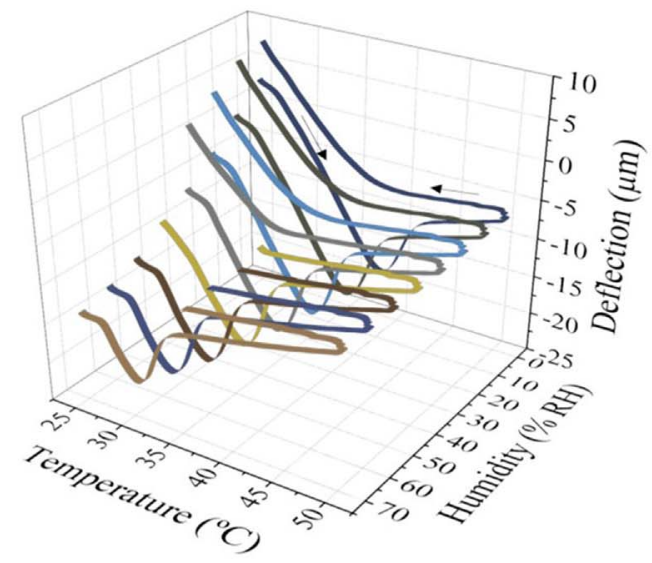

b)

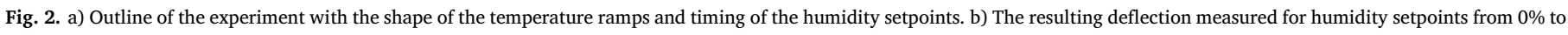
$70 \%$.

was measured using a Veeco Dektak $6 \mathrm{~m}$ profilometer. More details on the spray coating and its optimization can be found elsewhere [16].

\section{Results and analysis}

\subsection{Static cantilever deflection for $T_{g}$ measurements}

The $T_{g}$ of PLGA was measured by imposing temperature ramps at a constant rate while monitoring the deflection of the cantilever tip. The heating rate was $2{ }^{\circ} \mathrm{C} / \mathrm{min}$ from 25 to $50^{\circ} \mathrm{C}$. To dry the film, the humidity was maintained as low as possible using a flow of pure dry nitrogen for $30 \mathrm{~min}$. One initial temperature cycle was performed at this condition to erase the effects of physical aging in the curve; a 20-min humidity stabilization after cooling was used for all subsequent measurements. The humidity was increased from $10 \%$ to $70 \%$ in steps of $10 \%$ after a complete temperature cycle, as shown in Fig. 2(a).

At $10 \% \mathrm{RH}$, the polymer contains a very low amount of absorbed water, which induces a compressive initial stress in the cantilever by the polymer and bends the cantilever upward (Fig. 2(b)). During the heating cycle, thermal expansion of the polymer decreases the net stress until it reaches zero; further heating induces a tensile net stress in the cantilever structure. When $T_{g}$ is reached, the polymer viscosity and elastic modulus decrease, and the tensile net stress becomes completely relaxed, creating a net zero deflection between the uncoated and coated

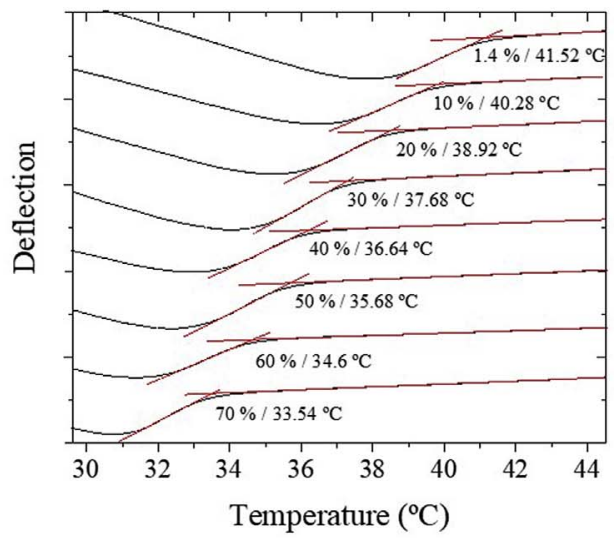

a) cantilever. During the cooling stage, a net deflection increase is observed when the temperature falls below $T_{g}$. Increases in humidity decrease the initial stress by swelling, and the initial deflection is inversely proportional to the humidity.

The hysteresis in the deflection curve between heating and cooling can be attributed to physical aging of the polymer below $T_{g}$ [6]. Below $T_{g}$, the polymer is in a non-equilibrium glassy state. Physical aging results from the slow dissipation of internal energy of the polymer toward equilibrium, which is mainly described by a volume decrease. Because of the higher molecular mobility, the internal energy and volume are recovered when the material is heated above $T_{g}$, indicating that physical aging is a reversible phenomenon [17].

For $T_{g}$ extraction, two tangent lines were fitted to the relaxation profile, as described previously [5]. The extraction for $10-70 \% \mathrm{RH}$ is shown in Fig. 3(a). One of the lines is fitted in the region after complete relaxation, while the other is fitted after the stress maximum. The $T_{g}$ value can be measured at the intersection of the two lines. As expected, an increase in the $\mathrm{RH}$ in the flow cell decreases the $T_{g}$ of the polymer by a plasticization effect. At $1.4 \% \mathrm{RH}, \mathrm{T}_{g}$ is $41.52{ }^{\circ} \mathrm{C}$ and decreases to $33.54^{\circ} \mathrm{C}$ at $70 \% \mathrm{RH}$.

PLGA can be produced with different molecular weights, and the $T_{g}$ value is higher for higher molecular weights [3]. The Resomer RG502 polymer has the lowest molecular weight, ranging from 7000 to $17000 \mathrm{Da}$. The $T_{g}$ value at $1.4 \% \mathrm{RH}$ is $41.5^{\circ} \mathrm{C}$, which is similar to the

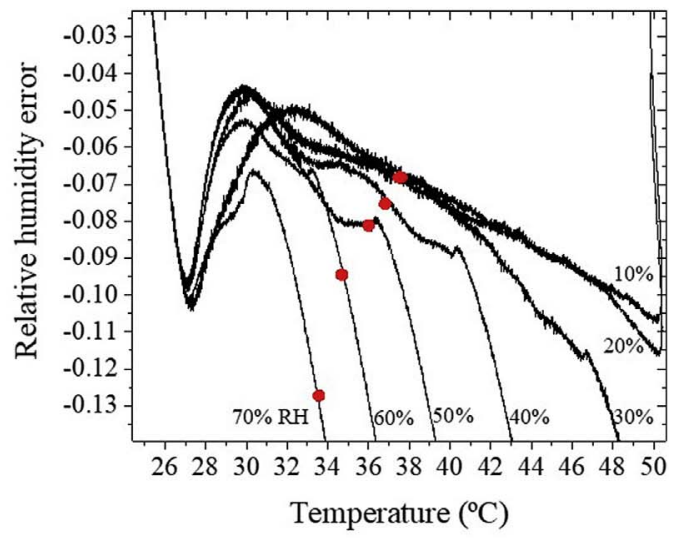

b)

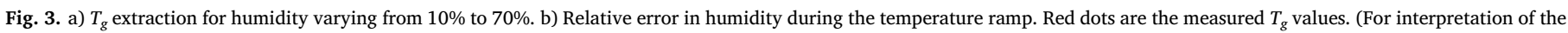
references to colour in this figure legend, the reader is referred to the Web version of this article.) 


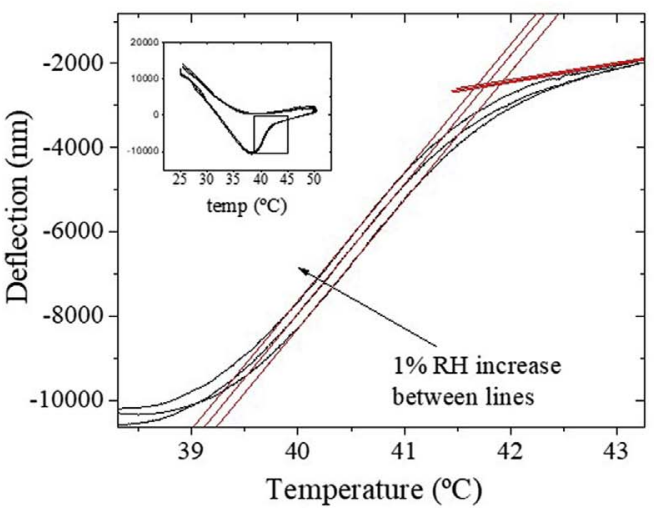

a)

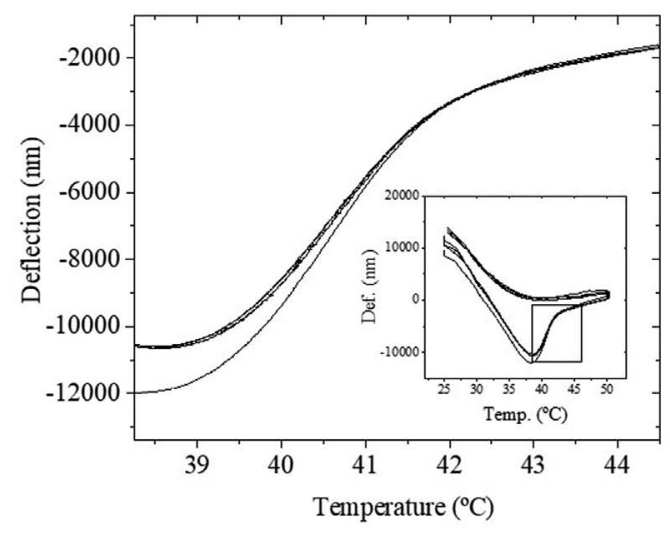

b)

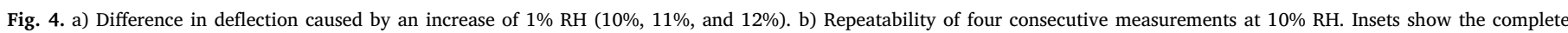
deflection curve and region where $T_{g}$ is extracted.

nominal $T_{g}$ range for RG502 $\left(42-46{ }^{\circ} \mathrm{C}\right.$ [18]). Different $T_{g}$ values are reported in the literature for RG502: $35^{\circ} \mathrm{C}$ [19], $40.04{ }^{\circ} \mathrm{C}$ [20] and $46^{\circ} \mathrm{C}$ [21].

The variation of humidity during the heating ramp is presented at Fig. 3(b). The relative error is measured from $e_{h}=(R H-S P) / S P$, where $\mathrm{RH}$ is the humidity measured at the cell and SP is the setpoint of the humidity. Maintaining a constant $\mathrm{RH}$ during heating is important because the equilibrium times for thin samples, such as those measured here, are faster than those for the bulk, and a decrease in $\mathrm{RH}$ can lead to less water inside the polymer.

The humidity initially decreases during the measurement due to inertia in the humidity control: the increase in the ratio of humidified gas does not immediately increase the humidity in the cell. At higher RH setpoints, $100 \%$ humidified gas at ambient temperature is not sufficient to maintain the $\mathrm{RH}$ setpoint of the cell as the temperature is increased, and the error in the humidity measurement can increase to more than $50 \%$. The relative error plot (Fig. 3(b)) shows that the $T_{g}$ (red dot) is measured before an important decrease in the humidity of the cell is observed. With the exception of the $70 \% \mathrm{RH}$ setpoint that was measured with an error of $13 \%$, all $T_{g}$ values were measured with relative errors in humidity of less than $10 \%$.

Fig. 4 shows the repeatability and resolution capabilities of the measurement system presented in this paper. In Fig. 4(a), increases of $1 \% \mathrm{RH}$ are clearly resolved by the deflection measurement. The $T_{g}$ values measured at $10 \%, 11 \%$, and $12 \% \mathrm{RH}$ are $41.914,41.753$, and $41.683^{\circ} \mathrm{C}$, showing that we can measure $T_{g}$ variations of less than $0.1^{\circ} \mathrm{C}$. Four consecutive measurements at the same $\mathrm{RH}$ condition are shown in Fig. 4(b), yielding a standard deviation of $0.025^{\circ} \mathrm{C}$. The first measurement of this series shows a slightly longer aging time; the deflection trace shows a higher stress peak than that of the other measurements at the same aging time.

\subsection{Measurement of the moisture mass content using the cantilever resonant frequency}

The resonant frequency of the first mode was measured by fitting a Lorentzian function to the resonant peak in the FFT of the FES. The cantilever was excited with a sweep frequency signal from 5 to $10 \mathrm{kHz}$ every $0.2 \mathrm{~s}$. The signal acquisition of the FES was triggered by the start of the sweep, and the FFT was averaged 10 times before a Lorentzian was fitted. During the initial $30 \mathrm{~min}$, a pure dry nitrogen flow was used to dry the sample, resulting in an $\mathrm{RH}$ of $6 \%$. Stepwise increases in humidity with $10 \%$ steps with a duration of 30 min were applied, and the results for the humidity, deflection, and resonant frequency are shown in Fig. 5.
The standard deviation of the frequency was measured as $0.5 \mathrm{~Hz}$, and $5-\mathrm{Hz}$ steps between $10 \%$ and $20 \%$ were clearly resolved by the system. The deflection and resonant frequency follow the humidity steps below $40 \% \mathrm{RH}$. The stabilization time of water uptake for the thin film is instantaneous. Quartz crystal microbalance (QCM) measurements indicate that the equilibration time for a $2 \mu \mathrm{m}$ PLGA film was approximately $5 \mathrm{~min}$ [11], which is less than the settling time of the humidity in our system.

Above 50\% RH, creep behavior is observed in the deflection curve. This indicates that a plasticization effect occurs and the relaxation times are smaller than those at lower humidity values. Under this condition, the elastic modulus of the film begins to decrease, and the effect can be seen in the frequency curve with a continued decrease at a constant humidity. For mass uptake analysis, the resonant frequency information was used for $\mathrm{RH}$ values below $50 \%$, where creep behavior is not observed and the elastic modulus is considered constant.

The amount of water in the polymer was estimated using the relation between the resonant frequency of the cantilever and its mass using the harmonic oscillator model:

$m_{\text {total }}=\frac{k}{f_{0}^{2} 4 \pi^{2} n}$

where $m_{\text {total }}$ is the sum of the polymer and silicon cantilever mass $\left(m_{\text {total }}=m_{\text {poly }}+m_{\text {canti }}\right), k$ is the effective cantilever spring constant, $f_{0}$ is the initial first mode resonant frequency, and $n$ is a constant to adjust the effective mass of the harmonic oscillator for a cantilever beam of

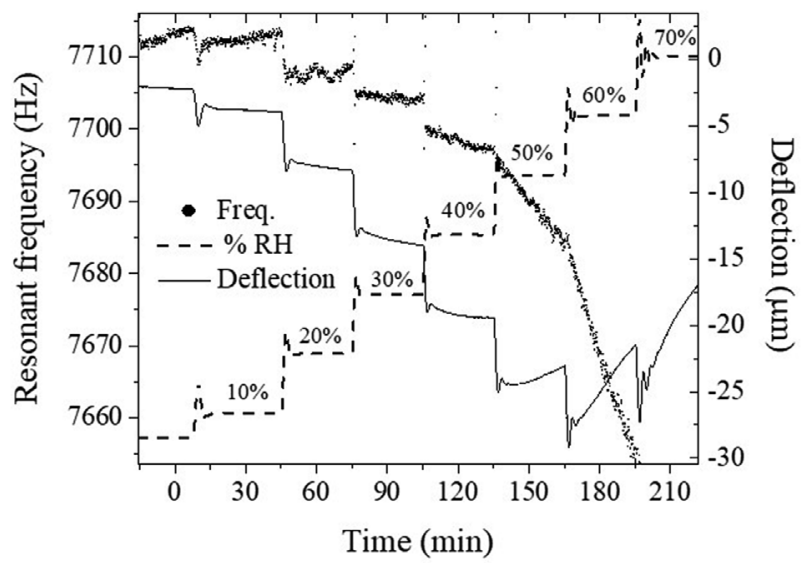

Fig. 5. Deflection and frequency measurement for stepwise increases in humidity at $25{ }^{\circ} \mathrm{C}$. 
$n=0.23$.

If the effective spring constant of the cantilever remains constant during the addition of mass and the relative resonant mass frequency change is small $\left(f+f_{0} \approx 2 f_{0}\right)$, the relative mass change can be simplified according to Eq. (3):

$\frac{\Delta m}{m_{\text {total }}}=-2 \frac{\Delta f}{f_{0}}$

where $\Delta m$ is the mass change $(\mathrm{kg})$ and $\Delta f$ is the change in frequency $(\mathrm{Hz})$. The water mass content in the polymer is given by the ratio in Eq. (4) if $m_{\text {poly }}$ and $f_{0}$ are the initial mass and frequency, respectively, for the dry polymer:

$\varnothing_{w}=\frac{\Delta m}{m_{\text {poly }}}$

where $\varnothing_{w}$ is the water mass content in the polymer. Equating Eqs. (3) and (4), the water mass content as a function of frequency is given by Eq. (5), where the mass content is proportional to the relative frequency change. The total mass and polymer mass can be calculated using the densities and geometries of the cantilever and polymer film. The cantilever chip is microfabricated with a very small variation in the dimensions, as demonstrated by the small variation in the resonant frequency $(<1 \%)$. The cantilever mass can be calculated from $m_{\text {canti }}=\rho_{s i} L w t$, giving a result of $116.4 \pm 0.1 \mathrm{ng}$.

$\varnothing_{w}=-2 \frac{m_{\text {total }}}{m_{\text {poly }}} \frac{\Delta f}{f_{0}}$

The polymer film presents an inhomogeneous profile after annealing, indicating refloating (Fig. 6(a)). To measure the area of the cross section, the profilometer was used in the region indicated by the white arrow in Fig. 6(a). The resulting cross section is shown in Fig. 6(b) with area $=2.3063 \times 10^{-10} \mathrm{~m}^{2}$. The polymer mass $(182.2 \pm 5.7 \mathrm{ng})$ was calculated from the density of PLGA $(1580 \mathrm{~kg} /$ $\mathrm{m}^{3}$ [10]). This amount is five orders of magnitude lower than the amount used in the DSC measurements $(\sim 5 \mathrm{mg})$.

Flory-Huggins theory has been largely used to describe the thermodynamics of polymer swelling [22]. The equation describes the activity of the solvent as a function of its mass in the polymer, as shown by Eq. (6):

$\ln \left(a_{w}\right)=\ln \left(\varnothing_{w}\right)+\left(1-\varnothing_{w}\right)+\chi\left(1-\varnothing_{w}\right)^{2}$

where $a_{w}$ is the water activity $\left(a_{w}=\% \mathrm{RH} / 100\right)$ and $\chi$ is the dimensionless interaction parameter that describes the interaction energy between the polymer and solvent. By equating Eqs. (5) and (6), an equation of $\mathrm{RH}$ as a function of the relative frequency change is given by Eq. (7).

$\ln \left(a_{w}\right)=\ln \left(-2 \frac{m_{\text {total }}}{m_{\text {poly }}} \frac{\Delta f}{f_{0}}\right)+\left(1-\left(-2 \frac{m_{\text {total }}}{m_{\text {poly }}} \frac{\Delta f}{f_{0}}\right)\right)+\chi\left(1-\left(-2 \frac{m_{\text {total }}}{m_{\text {poly }}} \frac{\Delta f}{f_{0}}\right)\right)^{2}$

Using the previously calculated mass parameter based on the geometry and densities, parameters $\chi$ and $f_{0}$ were fitted using Eq. (7) for the resonant frequency data (Fig. 5). The results are shown in Fig. 7(a) with a fitted interaction parameter, $\chi=3.11 \pm 0.03$, and initial frequency, $f_{0}=7716 \pm 0.3 \mathrm{~Hz}$. Previous QCM measurements [11] indicate an interaction parameter of $\chi=2.97$ for the PLGA/water system; this agrees with the value of $\chi$ obtained in this work.

The QCM measurement at $40 \% \mathrm{RH}$ indicates that PLGA absorbs around $0.6-0.7 \%$ water [11], which is compatible with the value obtained in this work. Titration values [10] for PLGA with a high molecular weight and equilibrated at $30 \%$ indicate that PLGA would absorb $0.82 \%$ of water; however, $0.5 \%$ was measured in this work. This difference can be attributed to the residual $0.3 \%$ mass of water, which was measured by titration.

The Gordon-Taylor theory is widely used to model the change of $T_{g}$ from mixing different materials. The equation indicates that when mixed, the resultant volume is the addition of the individual component volumes, as shown in Eq. (8):

$T g_{\text {mixture }}=\frac{\varnothing_{w} T g_{\text {water }}+k w_{\text {plga }} T g_{\text {plga }}}{\varnothing_{w}+k w_{\text {plga }}}$

where $T g_{\text {mixture }}$ is the glass transition temperature of the mixture, $T g_{\text {water }}$ is the glass transition temperature of water (in Kelvin; $138 \mathrm{~K}$ ), $w_{\text {plga }}$ is the mass fraction of PLGA, $T g_{\text {plga }}$ is the glass transition temperature of dry PLGA, and $k$ is an adjustment factor that can be approximated to $k=\rho_{\text {water }} T g_{\text {water }} / \rho_{\text {plga }} T g_{\text {plga }}$.

In Fig. 7(b), the Gordon-Taylor equation is fitted in the obtained $T_{g}$ versus mass fraction of water. The Gordon-Taylor theory agrees with the data in the studied range, suggesting that the absorbed water is evenly distributed inside the polymer. At this scale, $T_{g}$ depression is linearly dependent on the mass fraction of water $\left(\mathrm{R}^{2}=0.993\right)$, and the dry $T_{g}$ of PLGA is extrapolated to $41.24 \pm 0.07^{\circ} \mathrm{C}$. For RG502, $T_{g}$ decreases at a rate of $6.03 \pm 0.22{ }^{\circ} \mathrm{C}$ per mass $\%$ of water; this value agrees with that from Gordon-Taylor theory. The $T_{g}$ depression for RG503 measured by DSC and titration is $7.75^{\circ} \mathrm{C}$ per mass $\%$ of water [10]. This difference can be attributed to the limited range of water absorption studied here; at higher absorbed water masses, $T_{g}$ is no longer adherent to the Gordon-Taylor equation, and the measured $T_{g}$ is lower than that predicted for those cases.

Compared to similar sorption methods, such as QCM, dynamic cantilever mass sensing depends on the variation of the cantilever

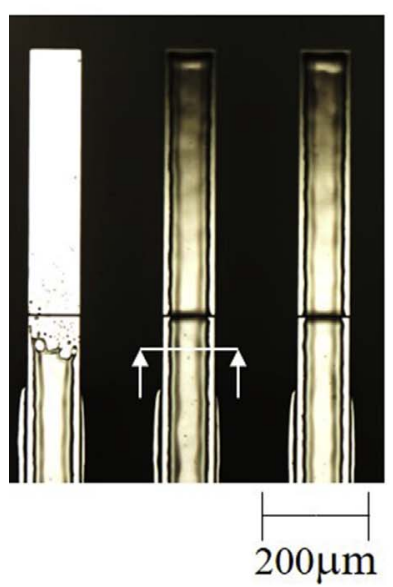

a)

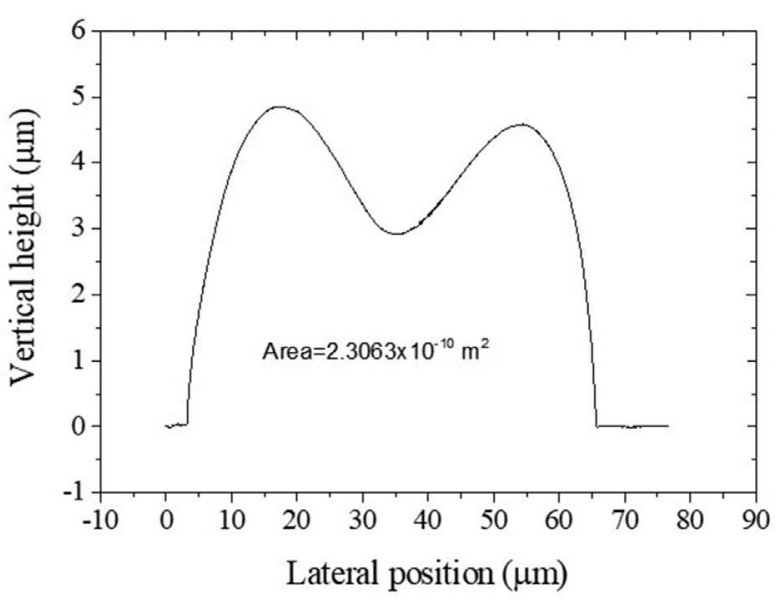

b)

Fig. 6. a) Optical microscope image of the PLGAcoated cantilever. The white arrow indicates the region where a profilometer was used to measure the cross section of the film. b) Cross section of the PLGA film for the cross-section area measurement. 


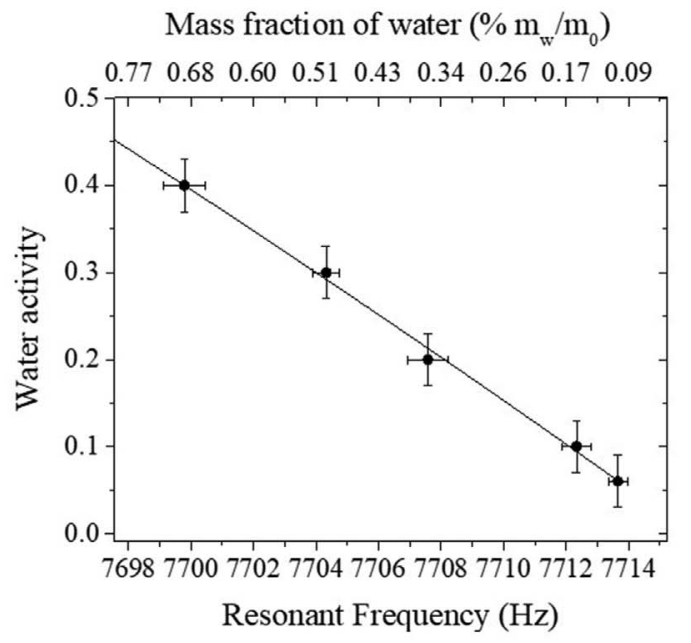

a)

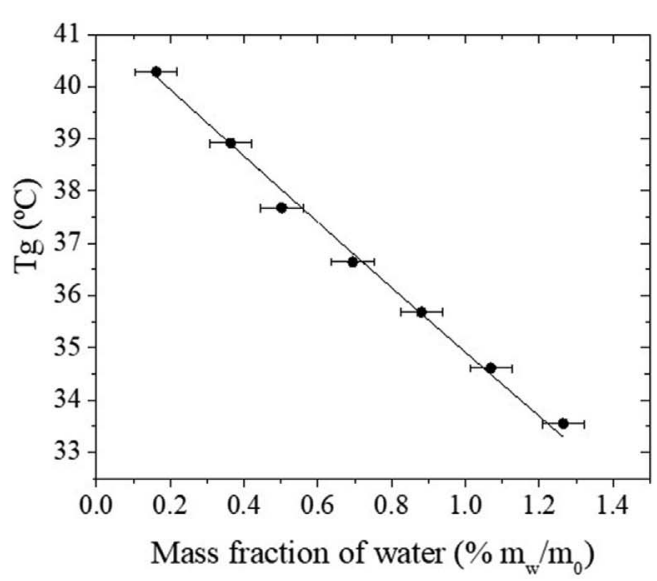

b)

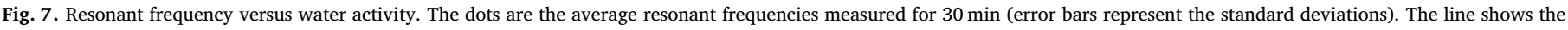

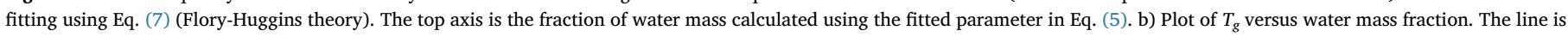

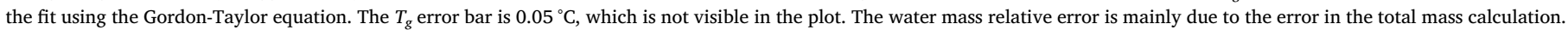

spring constant during the measurement. This variation can be minimized if the spring constant associated with the polymer is smaller than that of the cantilever. This can be achieved by stiffening the cantilever (using thicker dimensions) or by decreasing the film thickness. The consequence is a decrease in the deflection response and concurrent decrease in the static $T_{g}$ resolution. Both cantilever and QCM measurements provide several advantages over tradition bulk methods, such as sensitivity in the picogram range, real-time measurement capabilities, and nondestructive measurements. Both techniques are sensitive to mass addition, but are unable to measure the residual water in the polymer; techniques such as titration or thermogravimetric analysis are required to measure the absolute amount of water.

The mass resolution of the dynamic cantilever mass sensing is dependent on the noise and the minimum detectable frequency change [12]. Our system provides a standard deviation of the frequency of $0.5 \mathrm{~Hz}$. The relative polymer mass change that causes this frequency variation is on the order of $0.01 \%$ of the polymer mass, or around $20 \mathrm{pg}$.

\section{Conclusion}

This work showed a feasible study of the hygrothermal evolution of the glass transition temperature of polymers using microcantilever resonators in a low-cost experimental setup. The main advantage of using microcantilevers in this type of study is the simultaneous measurement of mass absorption and $T_{g}$ evolution using deflection and resonant frequency measurements. The use of thin films presents advantages beyond the use of nanograms of materials, enabling faster analysis because the moisture equilibrium times are orders of magnitude lower than those for bulk films.

The $T_{g}$ depression function of water solubility behaved linearly within the studied range $\left(\mathrm{R}^{2}=0.99\right)$. Both sorption theory (FloryHuggins) and mixing theory (Gordon-Taylor) agreed with the experimental data. The sorption measurements were compared to QCM studies with thin films of comparable thickness; similar amounts of absorbed water were observed. Less water was absorbed on the films than on the bulk material (measured by titration), possibly because the residual water in the film cannot be measured using the method described herein.

\section{Acknowledgments}

Funding: This work was supported by the Brazilian Agency $\mathrm{CNPq}$ [grant number 206605/2014-5] and Center for Intelligent Drug delivery and Sensing Using Microcontainers and Nanomechanics (IDUN), funded by the Danish National Research Foundation (DNRF122) and Villum Fonden (Grant No. 9301).

Conflicts of interest: There are no conflicts of interest to declare.

\section{References}

[1] B.C. Hancock, G. Zografi, The relationship between the glass transition temperature and the water content of amorphous pharmaceutical solids, Pharm. Res. 11 (1994) 471-477, http://dx.doi.org/10.1023/A:1018941810744.

[2] S.D. Allison, Effect of structural relaxation on the preparation and drug release behavior of poly(lactic-co-glycolic)acid microparticle drug delivery systems, J. Pharm. Sci. 97 (2008) 2022-2035, http://dx.doi.org/10.1002/jps.21124.

[3] P. Gentile, V. Chiono, I. Carmagnola, P. V Hatton, An overview of poly(lactic-coglycolic) acid (PLGA)-based biomaterials for bone tissue engineering. Int. J. Mol. Sci. 15 (2014) 3640-3659, http://dx.doi.org/10.3390/ijms15033640.

[4] N. Jung, H. Seo, D. Lee, C.Y. Ryu, S. Jeon, Nanomechanical thermal analysis of the glass transition of polystyrene using silicon cantilevers, Macromolecules 41 (2008) 6873-6875, http://dx.doi.org/10.1021/ma801539m.

[5] N. Jung, S. Jeon, Nanomechanical thermal analysis with silicon cantilevers of the mechanical properties of poly(vinyl acetate) near the glass transition temperature, Macromolecules 41 (2008) 9819-9822, http://dx.doi.org/10.1021/ma8020695.

[6] M. Yun, N. Jung, C. Yim, S. Jeon, Nanomechanical thermal analysis of the effects of physical aging on glass transitions in PS/PMMA blend and PS-PMMA diblock copolymers, Polymer (Guildf) 52 (2011) 4136-4140, http://dx.doi.org/10.1016/j. polymer.2011.06.051.

[7] M. Yun, C. Yim, N. Jung, S. Kim, T. Thundat, S. Jeon, Nanomechanical thermal analysis of photosensitive polymers, Macromolecules 44 (2011) 9661-9665, http:// dx.doi.org/10.1021/ma202194e.

[8] S. Bose, S. Schmid, T. Larsen, S. Sylvest Keller, A. Boisen, K. Almdal, Micromechanical fast quasi-static detection of $\alpha$ and $\beta$ relaxations with nanograms of polymer, J. Polym. Sci. B Polym. Phys. 53 (2015) 1035-1039, http://dx.doi.org/ 10.1002/polb.23745.

[9] S. Bose, S. Schmid, T. Larsen, S.S. Keller, P. Sommer-Larsen, A. Boisen, K. Almdal, Micromechanical string resonators: analytical tool for thermal characterization of polymers, ACS Macro Lett. 3 (2014) 55-58, http://dx.doi.org/10.1021/ mz400470n.

[10] P. Blasi, S.S. D'Souza, F. Selmin, P.P. DeLuca, Plasticizing effect of water on poly (lactide-co-glycolide), J. Control. Release 108 (2005) 1-9, http://dx.doi.org/10. 1016/j.jconrel.2005.07.009.

[11] J. S. Sharp, J. A. Forrest, R. A. L. Jones, Swelling of poly(dl-lactide) and polylactideco-glycolide in humid environments, 2001. https://doi.org/10.1021/MA011163Q. 
[12] A. Boisen, S. Dohn, S.S. Keller, S. Schmid, M. Tenje, Cantilever-like micromechanical sensors, Rep. Prog. Phys. 74 (2011) 36101, http://dx.doi.org/10.1088/ 0034-4885/74/3/036101.

[13] E.H. Hwu, K. Huang, S. Hung, Measurement of cantilever displacement using a compact disk/digital versatile disk pickup head, 45 (2006) 2368-2371, http://dx. doi.org/10.1143/JJAP.45.2368.

[14] A.C. Ceccacci, C.-H. Chen, E.-T. Hwu, L. Morelli, S. Bose, F.G. Bosco, S. Schmid, A. Boisen, Blu-Ray-based micromechanical characterization platform for biopolymer degradation assessment, Sensor. Actuator. B Chem. 241 (2017) 1303-1309, http://dx.doi.org/10.1016/j.snb.2016.09.190.

[15] A.L. Buck, A.L. Buck, New equations for computing vapor pressure and enhancement factor, J. Appl. Meteorol. 20 (1981) 1527-1532, http://dx.doi.org/10.1175/ 1520-0450(1981)020<1527:NEFCVP > 2.0.CO;2.

[16] S. Bose, S.S. Keller, T.S. Alstrøm, A. Boisen, K. Almdal, Process optimization of ultrasonic spray coating of polymer films, Langmuir 29 (2013) 6911-6919, http:// dx.doi.org/10.1021/la4010246.

[17] J.M. Hutchinson, Physical aging of polymers, Prog. Polym. Sci. 20 (1995) 703-760,
http://dx.doi.org/10.1016/0079-6700(94)00001-I.

[18] Resomer ${ }^{\circledR}$ RG 502, Poly(D,L-Lactide-co-glycolide) Lactide:glycolide 50:50, Ester Terminated, Mw 7,000-17,000 | Sigma-aldrich, (n.d.). http://www.sigmaaldrich. $\mathrm{com} / \mathrm{catalog} /$ product/aldrich/719889? lang = pt\&region $=$ BR. (accessed 9 March 2017).

[19] Effect of different ratios of high and low molecular weight PLGA blend on the characteristics of pentamidine microcapsules, Int. J. Pharm. 270 (2004) 251-262, http://dx.doi.org/10.1016/J.IJPHARM.2003.10.019.

[20] Peptide containing microspheres from low molecular weight and hydrophilic poly (d,l-lactide-co-glycolide), J. Control. Release 41 (1996) 249-257, http://dx.doi. org/10.1016/0168-3659(96)01332-6.

[21] W. Friess, M. Schlapp, Release mechanisms from gentamicin loaded poly(lactic-coglycolic acid) (PLGA) microparticles, J. Pharm. Sci. 91 (2002) 845-855, http://dx. doi.org/10.1002/jps.10012.

[22] J. Fried, Polymer Science and Technology, seco ${ }^{\text {nd }}$ ed., Prentice Hall, Upper Saddle River, NJ, 2003. 